\title{
Nueva York como marca promocionada por las series de televisión
}

García García, Pedro José

Universidad de Sevilla

http://dx.doi.org/10.12795/AdMIRA.2010.01.17

Resumen: Desde hace varias décadas, el cine ha servido como elemento indispensable en la comunicación turística de muchos países. Con el inicio del siglo XXI, la ficción televisiva norteamericana comienza una nueva edad dorada que contribuye a ampliar el concepto del 'turismo inducido por el cine'. Las series de televisión ambientadas en Nueva York proyectan una imagen de la ciudad que ha sido utilizada para su promoción turística internacional.

Palabras clave: televisión en Estados Unidos, imagen de marca, Nueva York, comunicación turística.

\section{Introducción}

La proliferación imparable de series de televisión norteamericanas en la actualidad es el resultado de una evolución en la ficción televisiva que da comienzo en lo que Robert Thompson llamó la segunda edad dorada de la televisión, y alcanza su mayor apogeo en los primeros años del siglo XXI, con los estrenos de dos series que van a redefinir el drama televisivo de cara a los años posteriores: Perdidos (Lost, 20042010) y Mujeres desesperadas (Desperate Housewives, 2004-). El éxito de estas series, junto al incipiente mercado de ficción de los canales de cable a finales de los noventa -con Los Soprano, de HBO, a la cabeza-, ha dado lugar a un crecimiento exponencial de la producción dramática de calidad a lo largo una década, lo que ha llevado a muchos a hablar de una tercera edad dorada de la televisión, que coincide con lo que otros autores han denominado la postelevisión o hipertelevisión.

La irrupción del mercado de DVD en los noventa y el increíble éxito de ventas de las series en este formato una década más tarde, junto al desarrollo de Internet y la televisión digital, ha dado lugar a una evolución en los modos de recepción de las series que ha afectado inevitablemente a su producción. La continua exposición a las series norteamericanas, ya sea por reposiciones en televisión, visionados en DVD o la tendencia más habitual en los últimos años, el visionado de episodios en Internet, contribuye más que nunca a la creación de mitos y a la perpetuación de estereotipos fuera de Estados Unidos. El éxito de los productos culturales norteamericanos en 
España ha desembocado en una progresiva reconfiguración de los hábitos sociales y culturales, que si bien no es responsabilidad exclusiva del cine o la televisión, no puede desligarse de ninguna manera de estos medios. Es evidente que series como Friends (1994-2004) han ejercido una gran influencia en los estratos más jóvenes de nuestra sociedad.

El cine norteamericano ha sido, sobre todo a partir de la década de los ochenta, uno de los principales instrumentos culturales de la globalización, ejerciendo como agente potenciador del turismo de su país. Es innegable la influencia que los éxitos cinematográficos ejercen en la promoción turística de un país, y esto se hace más evidente en el caso de Estados Unidos. Desde hace tiempo, se ha buscado una identificación por parte del espectador, con las historias y los personajes de las películas, que los acerquen a los lugares en los que estos están ambientados. El caso de Woody Allen, y su amplia filmografía, considerada por muchos un perenne homenaje a la ciudad de Nueva York, viene a ilustrar esta idea. En los últimos años, el fenómeno del turismo inducido por el cine se ha visto complementado por el que promueve la ficción televisiva a través de las series de éxito internacional.

Las localizaciones cinematográficas, los programas de televisión, etc. producen en el espectador una influencia consciente o no que le induce a incorporar a su imaginario personal los escenarios en donde se desarrollan sus obras audiovisuales preferidas, adonde les gustaría ir llevados de esa atracción. En definitiva, el cine influye sobre el turismo (Roscado y Querol, 2006:20).

A partir de finales de los noventa, con el éxito de la serie de HBO, Sexo en Nueva York (Sex and the City, 1998-2004), la televisión se convirtió en un nuevo agente turístico, que ha influido considerablemente en la promoción de la ciudad de Nueva York como destino, tanto dentro como fuera de Norteamérica.

En este trabajo, pretendemos analizar la imagen de la ciudad de Nueva York que las series de televisión de las dos últimas décadas han proyectado y perpetuado, y cómo estas han influido en la comunicación turística de Estados Unidos. Para ello, partimos de diversas teorías publicitarias con el objeto de elaborar un esbozo de la ciudad de Nueva York como marca a través de los estereotipos e iconos que las series difunden, para a continuación analizar cómo esta imagen de marca ha sido utilizada para potenciar la proyección turística internacional de la ciudad de Nueva York. 


\section{La creación de la marca 'New York'}

Las series norteamericanas ambientadas en Nueva York siempre han estado presentes en la televisión. Desde los inicios del medio como producto comercial a principios de los cuarenta, desarrollada en directo desde Nueva York y las primeras teleseries filmadas de los cincuenta, como I Love Lucy (1951-1957), la ciudad de los rascacielos ha servido de inspiración incomparable para la ficción televisiva. A partir de los noventa, se puede hablar de una proliferación de series ambientadas en Manhattan, siendo las sitcoms las más propensas a situar sus historias y personajes en la gran ciudad. Seinfeld (1989-1998), Loco por ti (Mad About You, 1992-1999), Spin City (1996-2002), Will \& Grace (1998-2006) y la más popular en nuestro país, Friends, son algunas de las comedias neoyorquinas de mayor repercusión, y las que más han contribuido al desarrollo de la imagen de la ciudad de Nueva York. Sin embargo, en la primera década del siglo XXI, el foco urbano más popular de la televisión se desplaza hacia otros lugares más inexplorados, como Miami (Dexter, CSI), Seattle (Anatomía de Grey), o núcleos urbanos más pequeños como Baltimore (The Wire) y pueblos -ficcionales- (Las chicas Gilmore, True Blood). No obstante, Nueva York quizás junto a Los Ángeles, pero en menor medida- sigue siendo el mayor exponente de representación y forja de identidad del país más allá de sus fronteras, a pesar de no condensar ni remotamente la realidad del vasto territorio norteamericano. Es por ello que quizás se esté dando el desplazamiento de los focos tradicionales de representación del que hablamos.

Nueva York es la marca norteamericana por excelencia, más que cualquier marca de producto de consumo, y a menudo, las series de televisión ejercerán como su publicidad. La publicidad institucional o las campañas de promoción turística, al ser percibidas como publicidad, tienen menor impacto cultural que las promociones -ya sean planificadas o involuntarias- realizadas por las series. Es decir, "no nos creemos de la misma manera las bondades de un producto si están anunciadas por el producto” (Baños y Rodríguez, 2003:22). Sin embargo, el mensaje es más efectivo cuando lo transmiten los personajes a los que admiramos, con los que nos sentimos identificados semana a semana. Las series hacen las veces de instrumento promocional de la ciudad de Nueva York, creando imágenes sobre una ciudad y un país, generalmente potenciando los aspectos más positivos del lugar y de la mentalidad de sus habitantes. Los protagonistas de las series ejercen de embajadores para los espectadores de todo 
el mundo. Sin embargo, debemos incidir en el hecho de que la imagen de marca de un lugar -que corresponde a la percepción que los consumidores tienen del mismo- es el resultado de la suma de todos los elementos que componen el lugar y las políticas de acción comunicativa utilizadas para comunicar las características y los elementos del lugar (Valls, 1992:29). Es decir, la influencia de las series de televisión es solo uno de los elementos que componen el complejo mecanismo que la comunicación pone en marcha para la creación de la imagen de una ciudad como Nueva York.

Una vez aclarado en qué consiste la imagen de marca de un lugar, “incidir en las cualidades positivas de una marca es una técnica muy eficaz en marketing. El propio país se convierte en marca” (Montes Fernández, 2007:164). Siguiendo la teoría de Montes Fernández, podemos afirmar que estas imágenes creadas por los productos audiovisuales norteamericanos llevan a la formación de estereotipos nacionales y a la consolidación y expansión de características culturales, susceptibles de ser utilizados para la creación de una identidad a través del cine y la televisión. En este sentido, las series elaboran una argumentación publicitaria con el propósito de transmitir una imagen de Nueva York fundamentada en valores como el placer, la inteligencia, la vanguardia, el poder adquisitivo o la amistad. Estos son valores que la hacen reconocible y la convierten en un producto atractivo para la audiencia. Como dice José Lorenzo González,

La marca es un signo distintivo que permite reconocer un producto entre todos los demás. Las marcas han pasado a ser uno de los mitos del siglo XX. Porque la marca no es solo un signo o un nombre, sino que además de identificar el producto pone en marcha connotaciones afectivas. (...) Las marcas se presentan asociadas a valores añadidos como prestigio, distinción, elegancia, nivel económico, popularidad o admiración. El éxito de una marca, frente a otras de igual calidad, no reside en el producto, sino en los valores añadidos (1988:239).

Sin embargo, es imposible comprobar si, en efecto, esta promoción de la marca de Nueva York es un hecho consciente llevado a cabo por las instituciones pertinentes de la ciudad, o por el contrario, responde tan solo a una necesidad narrativa convertida en coyuntura para el posterior beneficio turístico. Sabemos que Nueva York ofrece financiación a las películas y series cuyos rodajes se lleven a cabo en la ciudad, a través de programas estatales y créditos tributarios como el 'made in NY'. Sin embargo, concluir qué series se han beneficiado de esto, y en qué manera ha supuesto una promoción deliberada es imposible. 
Como ya hemos visto, la construcción de un lugar como marca se lleva a cabo por una parte a través de la forja y desarrollo de la imagen del lugar, del uso de los estereotipos y las características culturales, y por otra de la elaboración de metáforas e iconos -este último elemento analizado en el tercer punto. Veamos detenidamente estos elementos aplicados al caso de Nueva York como marca a través de las series de televisión.

La imagen que proyecta un país fuera de sus fronteras es determinante para las relaciones bilaterales y multilaterales en cuanto a intercambio económico, social y cultural. El turismo es una fuente de ingreso inestimable para muchos sectores de un país. La promoción de una imagen abierta, moderna y cosmopolita asociada a un país es un factor de marketing indispensable en el mundo globalizado en el que vivimos (Montes Fernández, 2007:164).

En este sentido, podemos concebir la proliferación en los noventa de series norteamericanas que potenciaban los valores de la amistad, el cosmopolitismo y la riqueza cultural frente a la delincuencia, las drogas y el caos urbano de la década anterior como un lavado de cara, con la intención de proyectar una imagen renovada de la ciudad para el resto del mundo. Se puede hablar pues de 'las series de Giuliani', que vienen a barrer bajo la alfombra los problemas heredados de la etapa en la alcaldía de Edward I. Koch, en la que la epidemia del crack incrementó la delincuencia y proyectó una imagen esencialmente negativa de la ciudad. La marca había sido abandonada por sus anunciantes, ya no ofrecía seguridad y confianza, por lo que se hacía necesario devolverle estos atributos para hacerla anunciable de nuevo. Las sitcoms neoyorquinas hicieron campaña de la nueva Manhattan, pero había una variable que añadía un matiz muy importante: todas estas comedias se rodaban en estudios de Hollywood, por lo que no fueron pocas las críticas relacionadas con el grado de verosimilitud y fidelidad de estas series con la realidad de la ciudad. A pesar de esto, series como Friends resultaron ser efectivas campañas de promoción de Nueva York, proyectando una imagen idealizada de la ciudad.

El impacto de las series de televisión de cable a finales de los noventa va ejercer de contrapunto a las sitcoms neoyorquinas filmadas en Los Ángeles. Las ya mencionadas Sexo en Nueva York y Los Soprano (1999-2007) se grababan en localizaciones de Nueva York y el vecino estado de Nueva Jersey. La Nueva York que retrataban estas series -en el caso de Los Soprano, que se ambientaba en Nueva Jersey, solo de manera ocasional- se distanciaba radicalmente de la ciudad de cartón piedra que 
promovían las sitcoms, y acercaban al espectador a un paisaje urbano real, en el que la presencia -a menudo aislada- de la delincuencia, las drogas y el sexo aportaba credibilidad, sin por ello desarrollar una imagen negativa de la ciudad. A pesar de algunas críticas -que más bien se centraban en la perpetuación de estereotipos de género y de nacionalidades como la italiana- ambas series lograron crear una imagen de Nueva York más acorde a la que el público internacional estaba acostumbrado a ver en el cine. Sobre todo Sexo en Nueva York consiguió convencer a la audiencia de que Nueva York era una ciudad vibrante, atractiva y dinámica. Esto, como veremos en el último punto de este trabajo, desembocó en una auténtica revolución turística. Más recientemente, HBO ha estrenado otra serie, How to Make It in America (2010), cuya acción también transcurre en Nueva York -y sin embargo, no se llama How to Make It in New York- y que ya desde la cabecera de inicio manifiesta la tendencia de la cadena a mostrar la diversidad reinante en la ciudad.

Por otra parte, es curioso observar cómo estas series de televisión -y no solo las ambientadas en Nueva York- han acercado al espectador internacional a una serie de marcas que o bien acaban extendiéndose fuera de Estados Unidos, o sirven como reclamo turístico para aquellos que desean vivir una experiencia lo más cercana posible a lo visto en pantalla.

La imagen de un país se construye y se forja a través de sus marcas que se convierten en insignia. Las marcas, por una parte, poseen ante el consumidor atributos tan positivos como credibilidad, fiabilidad y calidad, todo ello cualidades que conllevan que destaquen entre los demás productos de la misma categoría. Por una parte, destaca el componente psicológico, ya que representan símbolos de un conjunto de actitudes en los que el consumidor confía intuitivamente. Las marcas apelan a los sentimientos y las emociones del consumidor que proyecta en ellas valores como confianza, seguridad y felicidad, tan anheladas para su propia vida. Es por ello que resultan fascinantes, ya que proyectan un estilo de vida y un mundo imaginario al que merece la pena pertenecer (Montes Fernández, 2007:165).

En el caso de Nueva York, son las marcas relacionadas con las compras y la comida las que más influencia ejercen en la forja de la imagen internacional de la ciudad. Los fans de estas series de televisión reconocerán al visitar la ciudad lugares esencialmente neoyorquinos, como los establecimientos de alimentación Grey’s Papaya o Dean \& Deluca, y department stores como Macy's o Bloomingdale’s, sin olvidar la omnipresente joyería Tiffany's, todos ellos vistos con frecuencia en la ficción televisiva. 
Los estereotipos nacionales que las series de televisión nos transmiten sobre Nueva York y sus habitantes son otro de los elementos clave para la construcción de la ciudad como marca.

Las imágenes estereotipadas se basan en convicciones culturalmente determinadas que poseemos acerca de las características, de las cualidades y de los atributos personales sobre un grupo de personas pertenecientes a otras culturas. (...) Los estereotipos atribuyen un cierto orden al desorden evidente de la compleja realidad. Para ello, tienen que reducir la realidad a modelos sencillos basados en pocas características que ayudan así a entender la complejidad social. Se trata por tanto de una categorización simplificada de la realidad (Montes Fernández, 2007:166).

Los personajes televisivos neoyorquinos tienden a ser personas inteligentes y activas, pero también neuróticas e inseguras (Carrie de Sexo en Nueva York, Ted de Cómo conocí a vuestra madre o Mónica de Friends son algunos ejemplos). Esta estereotipación del joven manhattanite no responde sino a una necesidad narrativa y argumental, que sin embargo ha servido para proyectar una imagen muy concreta de la ciudad. Debemos entender, no obstante, que este tipo de personajes, quizás más propensos a ser encontrados en una urbe de las características de Nueva York, no son únicos representantes de una ciudad o un país. Es más conveniente para el desarrollo narrativo de una serie de televisión y su proyección comercial que un personaje de ficción sea emocionalmente inestable o conflictivo, pero este tipo de personaje no debe tomarse como referente único. Por otra parte, los estereotipos que definen los habitantes de la ciudad de Nueva York en las series de televisión se concentran en la clase media-alta, obviando otros estratos de la sociedad.

Además de los estereotipos, las características culturales del país son otro de los factores que contribuyen a la imagen de la ciudad sin prestar demasiada atención a otras realidades que no sean la juventud acomodada -How to Make It in America parece nacer para suplir ese déficit. Edward T. Hall analiza el modo en que los norteamericanos usan el tiempo, el espacio y el contexto y cómo se comunican a través de estas variables. Su análisis está repleto de elementos familiares para el lector, tanto el norteamericano como el extranjero. Advierte que "el análisis de la cultura propia hace explícitas las muchas cosas que damos por sentadas en nuestra vida diaria. Hablar sobre estas cosas, sin embargo, cambia nuestra relación con ellas” (Hall, 1989:168). La continua exposición del espectador español a la cultura norteamericana, a través del cine y la televisión produce un fenómeno de familiaridad 
que no se repite con ninguna otra cultura, al menos no a un nivel tan profundo. Siguiendo el modelo de análisis de Hall, podemos concluir que la marca Nueva York se completa con las siguientes características culturales: el cumplimiento estricto de horarios y la importancia del trabajo; el dominio del territorio físico que ejercen los ciudadanos de Nueva York gracias al aislamiento, la independencia y la protección que aportan las cualidades geográficas de la ciudad de Manhattan; y la comunicación directa y explícita en una cultura de bajo contexto, en la que no existen apenas ambigüedades y quedan bien establecidas las reglas que organizan la vida social y cultural.

Por último, las metáforas culturales forman parte de la imagen estereotipada de las diferentes culturas que recibimos a través de los medios de comunicación. Martin J. Gannon utiliza la metáfora del fútbol americano para explicar a grandes rasgos la cultura norteamericana. El fútbol está presente en las series neoyorquinas, especialmente en las sitcoms de los noventa, en tanto en cuanto supone un motivo de reunión social en torno a un evento nacional -la Super Bowl-, que a menudo sirve como marco perfecto para desarrollar tramas de compañerismo. Para Gannon, además, la metáfora del fútbol sirve para transmitir "una serie de ideales y creencias en común; de hecho, el fútbol es un conjunto de rituales colectivos y valores compartidos por una sociedad dinámica” ${ }^{1}$ (2004:207).

\section{Nueva York, marca emplazada}

Una vez establecidas las características de la marca Nueva York, veamos cómo ésta es emplazada en las series de televisión. Debemos señalar que la selección de las series analizadas en este trabajo responde a un criterio objetivo a través del cual hemos valorado cuáles son las series norteamericanas que mayor repercusión han tenido en nuestro mercado, recurriendo a algún título de menor impacto, que sin embargo nos resulta imprescindible abordar para ilustrar algunas de las ideas desarrolladas a continuación.

1 Traducción del autor 
La televisión sigue siendo a día de hoy, y a pesar del desarrollo imparable de Internet, el medio más eficaz para la publicidad. La estrategia de la publicidad por emplazamiento, o como es más conocida popularmente, product placement, consiste en la promoción de una marca insertada en los mecanismos narrativos del producto audiovisual, ya sea mostrándola o refiriéndose a ella. Ya que el emplazamiento no tiene por qué ser exclusivamente de un producto de consumo, sino que también se puede emplazar una campaña de concienciación social o un destino turístico, podemos acercar la noción de product placement a la idea de Nueva York como marca que hemos estado manejando hasta ahora. En muchos casos, es complicado concretar si la aparición de la marca es una estrategia publicitaria que modifica el guión o si por el contrario responde a una necesidad narrativa previamente establecida. En el caso de los destinos turísticos, podemos diferenciarlo más fácilmente. Y concretamente, en el caso de Nueva York, no podemos negar que la aparición de la ciudad en una serie es generalmente una clara exigencia de guión. Sin embargo, esto no quiere decir que la ciudad no se haya beneficiado de esta publicidad -insisto, no sabemos si gratuita o no-, por lo tanto, no es descabellado pensar en la aparición de la ciudad en las series y en la relación de sus protagonistas con la misma como un caso de product placement a gran escala. "El mensaje se recibe y cumple una misión en el público independientemente de la posible relación económica entre la marca y la productora. Por lo tanto, dadas las actuales circunstancias, el dinero no lo es todo en el product placement. (...) Pagar o no pagar no es suficiente para identificarlo y, mucho menos, para definirlo” (Baños y Rodríguez, 2003:35).

Sin duda, Nueva York es uno de los casos más paradigmáticos de localización que traspasa las fronteras narrativas del espacio para convertirse en personaje de la ficción en la que aparece. Es habitual encontrar en las series de televisión multitud de homenajes a la ciudad, que constituyen auténticas declaraciones de amor de los protagonistas. La relación de los personajes de las series con Nueva York es una relación de amor -en pocas ocasiones de amor y odio- que no hace sino potenciar la imagen positiva que los espectadores percibimos. "Las posibilidades de que se transmitan las cualidades de la marca, o que se incremente su imagen por la asociación a los personajes y situaciones narrativas, aumentan cuando se traspasa la simple presencia o utilización y el objeto comercial deja de ser mudo comparsa o lacayo de la acción para presentarse como elemento activo de la narración” (Baños y 
Rodríguez, 2003:85). Veamos las distintas relaciones de los personajes de las series analizadas para este trabajo con la ciudad de Nueva York, y cómo estas influyen en la imagen de marca de la ciudad.

En primer lugar nos detendremos una vez más en el caso de las sitcoms de los noventa. Cuatro años después del estreno de Friends, cuando la serie gozaba de sus años de mayor popularidad internacional, se le unió Will \& Grace, junto a la que formó una indestructible coalición que se llegó a conocer como "los jueves de comedia de NBC”. Como hemos visto en el apartado anterior, estas series se rodaban en estudios en Los Ángeles, y solo los planos recurso de exteriores estaban previamente rodados en Nueva York. La universalidad el humor de Friends acerca a las audiencias de todo el mundo a una ciudad globalizada como Nueva York y la relación 'romántica' de sus seis protagonistas con la ciudad le otorga el encanto necesario para atraer visitantes en busca de las experiencias idealizadas que ven en la pequeña pantalla. La paradoja reside en el hecho de que la Nueva York de Friends está profundamente falseada. Quizás esta sea una de las claves del éxito de la serie dentro y fuera de sus fronteras, la necesidad de vivir una fantasía escapista, que en caso de la audiencia española, ofrecía un humor refinado y unos personajes sofisticados en oposición a las series de ficción española.

Caso aparte es el de Felicity (1998-2002), de JJ Abrams, una serie dramática -con episodios de 40 minutos de duración- ambientada en Nueva York, pero rodada en Los Ángeles, como las sitcoms de NBC. La protagonista de Felicity se mudaba a la ciudad de Nueva York para empezar sus estudios universitarios, persiguiendo a su amor de instituto. La Nueva York de Felicity, a pesar de estar reconstruida, evidenciaba un mayor esfuerzo por imbuirse del verdadero espíritu de la ciudad, mostrando a menudo aspectos mucho menos presentes en las comedias, como la vida nocturna o el metro. Sin embargo, Felicity era, como Friends, una historia sobre personas en busca del amor y de un lugar en el mundo.

Volviendo a las sitcoms, al igual que Friends, Will \& Grace es un relato altamente ficcional sobre Nueva York. Sin embargo, la serie protagonizada por un abogado gay y una diseñadora de interiores heterosexual parece albergar un mayor grado de compromiso con la realidad social de la ciudad. Aunque para muchos, esto no es más que una ilusión. La imagen de Nueva York potenciada por Will \& Grace es la de una 
ciudad amigable y tolerante, que se antoja altamente utópica. Nueva York es en este caso un espacio totalmente ficticio del que la serie que toma interesadamente los aspectos más amables de la ciudad y los potencia para construir un mundo en el que sus personajes puedan vivir en armonía. De la misma manera que, según Samuel A. Chambers (2009), Will es un personaje gay que no es utilizado para contarnos qué supone ser homosexual, Will \& Grace recurre a la ciudad de Nueva York, pero no para hablarnos de ella, sino para usarla como apoyo para su discurso progresista y liberal. "La marca es fundamental, pero más importante es la idea que cada uno de nosotros tiene de esa marca, los valores que le asociamos y que, ni mucho menos, están basados en características objetivas, al menos exclusivamente” (Baños y Rodríguez, 2003:219).

Las sitcoms de NBC triunfaron por la construcción de sus personajes, y la calidad de su humor, pero no lograron transmitir una imagen certera (o real) de la ciudad, mientras que otras series de otras cadenas como HBO se permitieron el lujo de rodar en exteriores de Manhattan, ahorrándose la tarea de reconstruir la ciudad y aprovechando su imaginario real para construir sus historias, y no el imaginario colectivo depurado que habían difundido Friends o Will \& Grace. La política de programación de la cadena permitía la emisión de productos con altas dosis de sexo y violencia. Era la oportunidad perfecta para mostrar una Nueva York más desnuda, atrevida, sexy y adulta en oposición a Friends, que era, injustamente, la comedia neoyorquina por excelencia -con permiso de Seinfeld, de menor repercusión internacional. Sexo en Nueva York era el vehículo perfecto para llevar a cabo este propósito. La serie -cuyo título original omite el nombre de la ciudad- presenta una relación de amor incondicional entre las protagonistas y Manhattan. Nueva York es representada como un paraíso de compras, una enorme pasarela de moda y un gran bar nocturno en el que buscar pareja. Además, Nueva York también es la familia, pero no la tradicional, sino la que representan los amigos- idea presente en casi todas las series neoyorquinas.

Junto con la amistad, es incuestionable que la ciudad de Nueva York se configura como un elemento esencial dentro de los elementos narrativos que componen la serie. Es, como muchas veces reconocen los guionistas, casi un quinto personaje protagonista y su presencia se hace indiscutible tanto en los elementos de contenido de las tramas como en los aspectos icónicos que definen la serie. Además, se convierte en una especie de microcosmos conducido por la 
pulsión sexual de las protagonistas, e incluso, se vuelve un novio metafórico en una de las crónicas de Carrie ('Levando anclas’) (Gordillo, 2009:193).

Por tanto, Nueva York es una de las chicas cuando estas necesitan compañía en una noche solitaria después de una ruptura sentimental, o se convierte en un novio -que ofrece estabilidad y seguridad- cuando una de ellas decide no seguir buscando el amor de su vida.

Según esta serie, Nueva York proporciona el contexto idóneo para la mujer trabajadora que aún no ha creado una familia o no piensa hacerlo. Es habitual en las series neoyorquinas que la mujer trabajadora forme una familia y desee salir de Manhattan en busca de un ambiente más propicio para criar a sus hijos. Es el caso de Mónica en Friends o de Miranda en Sexo en Nueva York. Ésta última, sobre todo, ilustra esta idea durante toda su andadura. Según la serie, Nueva York no es una ciudad familiar, es una ciudad para jóvenes o solteros que han decidido casarse con su profesión. Esto ha dado lugar a críticas desde el principio. "El hecho de que todas vivan en apartamentos acomodados en Manhattan muestra que pertenecen a un grupo reducido y privilegiado de jóvenes profesionales que pueden llevar vidas independientes y sin pareja. Desde esta perspectiva, Sexo en Nueva York invisibiliza las cuestiones de estatus social, trabajo y poder social de las mujeres” 2 (Bignell, 2004:217). Los estudios analíticos sobre la serie se han centrado en cuestiones de representación de género y han apuntado en muchas ocasiones que la ciudad de Nueva York es el espacio publicitario perfecto para 'vender' una imagen, un tipo de mujer. Manhattan es para muchos otro accesorio de las protagonistas que las espectadoras desean poseer, a pesar de que para ellas, esta es mucho más que un collar o unos zapatos. El fulgurante éxito de Sexo en Nueva York ha generado ya en la era de la hipertelevisión otras series ambientadas en Nueva York y protagonizadas por mujeres profesionales, como Mujeres en Manhattan (Lipstick Jungle, 2008-2009) o Cashmere Mafia (2008), que sin embargo han resultado ser fracasos de audiencia.

Tras una etapa en la que otras ciudades o pueblos toman el relevo de Nueva York en la ficción televisiva norteamericana, la gran ciudad parece gozar de nuevo de una presencia destacada en la pequeña pantalla. Son principalmente dos series las que renuevan el interés por las historias ambientadas en Manhattan: la sitcom de CBS

\footnotetext{
2 Traducción del autor
} 
Cómo conocí a vuestra madre (How I Met Your Mother, 2005-) y el drama adolescente de The CW, Gossip Girl (2007-). Cómo conocí a vuestra madre ha sido comparada con Friends desde el inicio de su andadura. Y lo cierto es que en una etapa de la televisión en la que las sitcoms de risas enlatadas rodadas en Los Ángeles están de capa caída, Cómo conocí a vuestra madre viene a rellenar el hueco dejado por la comedia de NBC. La de CBS es otra historia sobre un grupo de amigos que se acercan a la treintena. Sin embargo, la complejidad narrativa de Cómo conocí a vuestra madre las distancia considerablemente. "Si el producto audiovisual está bien construido, el espectador al consumirlo desata una serie de mecanismos de implicación emocional con lo mostrado en la ficción, que le llevan a asociar lo visto con sus propias experiencias” (Baños y Rodríguez, 2003:75). En ese sentido, Cómo conocí a vuestra madre juega con esta identificación a través de los pequeños detalles que acercan la ciudad a los espectadores, a través de historias sencillas y anecdóticas que nos muestran el día a día en la ciudad, y que presentan Manhattan como un lugar alcanzable y abarcable. Cómo conocí a vuestra madre saca el mayor provecho a los exteriores recreados en el estudio, pero sigue sin mostrarnos la verdadera Nueva York, aunque lo intente a través de astutas argucias narrativas.

Gossip Girl, por el contrario, se filma en localizaciones reales de Manhattan, y sin embargo, no logra -ni le interesa- mostrar el fresco étnico y la realidad social de la ciudad. Ambientada en el Upper East Side, uno de los barrios más privilegiados de Manhattan, la serie de The $C W$ se centra en las vidas de un grupo de adolescentes ricos y sus padres. De hotel de cinco estrellas a apartamentos-mansión, los protagonistas de Gossip Girl crean tendencia y se pasean por las calles de la ciudad, que al igual que sucedía en Sexo en Nueva York, se convierte en pasarela de moda y en portada de revista.

Para finalizar, en los últimos años, existe una tendencia en la televisión norteamericana por mostrar los entresijos de distintos universos laborales, aspecto ciertamente ignorado o tratado como complemento necesario $-\mathrm{y}$ a menudo forzadode las biografías de los protagonistas. Series como Daños y perjuicios (Damages, 2007-2010), Rockefeller Plaza (30 Rock, 2006), Betty (Ugly Betty, 2006-2010), y la más reciente, How to Make It in America, muestran una ciudad de Nueva York cuyo ritmo es imprimido por el día a día de los profesionales de diversas ramas. A través del culto al profesionalismo, Nueva York se nos presenta como el lugar al que acudir 
para desarrollar una carrera de éxito. En el episodio "New York Sucks” (2.07) de Daños y perjuicios, un personaje -no nos interesa identificarlo- le dice a su sobrina en respuesta a la frase que da título al episodio: "Cuando tu tatarabuelo se marchó de Escocia, vino a Nueva York. Es la tierra de las oportunidades. Si un hombre es honesto y trabaja duro, si es productivo, no puedes ni imaginar todo lo que puede lograr aquí”. A través de la relación de los personajes de estas series con la ciudad, percibimos Nueva York como el destino idóneo para alcanzar el éxito profesional, en concreto en los campos en los que la ciudad despunta: la abogacía (Daños y perjuicios), la moda y el arte (Betty, How to Make It in America) o la televisión en directo (Rockefeller Plaza).

A modo de conclusión de este apartado, los personajes de las series 'profesionales', junto a los del resto de series comentadas, ejercen de protagonistas de grandes spots que venden la ciudad de Nueva York como un lugar donde alcanzar el éxito profesional, estar a la vanguardia de la moda o encontrar el amor y vivir experiencias inolvidables.

\section{Proyección turística de Nueva York a través de las series}

Existe un placer genuino por el reconocimiento de los territorios propios de los personajes, un mapa emocional de identidad figurativa. El carácter totémico de estos espacios originarios comporta vínculos sentimentales profundos, que el receptor de la ficción asume como propios. Los espacios seriales adquieren memoria y dimensión mítica. Algunos se convierten en monumento cultural autónomo, que puede ser reutilizado por ficciones de todos los tiempos. Eso explicaría la fertilidad serial de algunas tramas que han sabido identificar un lugar nuclear y convertirlo en denominador común, sello de identidad (Balló y Pérez, 2005:35).

El placer del que hablan Balló y Pérez ha sido aprovechado desde hace varias décadas por las agencias de viaje para promocionar sus destinos, ampliando el reclamo de la mera observación de los lugares con la posibilidad de implicación absoluta del visitante con estos, dando la oportunidad de recrear vívidamente como protagonista lo experimentado como espectador de cine. Como indican Roger Riley, Dwayne Baker y Carlton S. Van Doren, “ampliando el ámbito conceptual, encontramos razones adicionales por las cuales el cine induce a las personas a viajar. Originalmente, se pensaba que las razones se limitaban al disfrute de los paisajes naturales, pero las 
tramas, escenas emocionantes y las relaciones humanas pueden hacer también que el público visite estas localizaciones” ${ }^{3}$ (1998:920). En relación a esto, los mismos autores señalan la importancia de los iconos representados en las películas como elemento clave para comprender la atracción que ejercen los escenarios de cine:

Los distintos tipos de cualidades atractivas que inducen a las personas a viajar son tan diversos como las películas en las que residen. Parece que si una parte de una película es extraordinaria o seductora, sirve como icono que los espectadores vinculan a una localización mostrada en la película. Con el término 'icono' se implica que el contenido simbólico de una película, un evento dentro de ella, un actor favorito, las cualidades físicas de una localización o un tema pueden representar toda la popularidad y el atractivo de una película. Los iconos, abstractos o tangibles, se convierten en el punto central de visitas y el lugar asociado es una evidencia tangible del icono (1998:923).

Lo mismo ha ocurrido en la televisión desde finales de los noventa, concretamente a partir del caso de Sexo en Nueva York. Nueva York pasa de ser espacio cinematográfico - un gran plató de cine- a espacio serial, como indican Balló y Pérez (2005:35). La búsqueda de los iconos representados en las series neoyorquinas ha desembocado en una estrategia turística que comenzó con los rutas organizadas para visitar los lugares frecuentados por las protagonistas de Sexo en Nueva York, y que se ha visto ampliado recientemente con tours de Seinfeld, Los Soprano y Gossip Girl. El icono que sin duda más ha influido en la comunicación turística de la ciudad de Nueva York y su proyección internacional es el de la vanguardia, el cosmopolitismo y el poder adquisitivo vinculado. Es por ello que el tour de Sexo en Nueva York-que en 2008 recibió un enorme impulso con el estreno de la versión cinematográfica de la serie- ha sido el más popular hasta ahora. A través del Sex \& the City Tour, símbolo del desarrollo del turismo femenino en la ciudad, las turistas visitan la casa del West Village que sirvió como exterior del apartamento de Carrie, la tienda de muebles Furniture Company -lugar de trabajo de uno de los novios de la protagonista-, o el barrio Meatpacking District -icono de la moda y la vanguardia, donde reside Samantha, otra de las protagonistas-, junto con el sinfín de tiendas, bares y restaurantes fetiche de los personajes de la serie. Tanto esta ruta, como el tour de Gossip Girl, llamado Gossip Girl Walk, son construidos de acuerdo a los devenires narrativos de ambas series. Ambos tours están diseñados para mujeres de alto poder

\footnotetext{
3 Traducción del autor
} 
adquisitivo, característica que el Gossip Girl Walk tiene menos reparos en disimular. Cada parada de la ruta insta a las turistas a gastar dinero para vivir la experiencia del Upper East Side tal y como se muestra en pantalla -móviles, ropa, tratamientos de belleza-, llegando a indicar en la guía los desorbitados precios de todos los productos disponibles.

Otras rutas mucho más asequibles y menos exhaustivas -como la organizada por On Location Tours, que incluye localizaciones de varias series en una sola visita- llevan a los visitantes a lugares como el edificio que sirve de exterior del apartamento de los protagonistas de Friends -en Greenwich Village- o los restaurantes que frecuentan los protagonistas de Seinfeld, el "Monk" o el "Soup Nazi”. La ruta de Los Soprano supone una vuelta de tuerca a este tipo de recorridos turísticos, puesto que el icono que utilizan para atraer al turista es el del crimen, haciendo paradas en los lugares en los que algún personaje fue asesinado.

Estos tours han sido incluidos en la primera campaña global de comunicación para la promoción turística de Nueva York, puesta en marcha por el alcalde Michael R. Bloomberg, con el propósito de alcanzar los cincuenta millones de visitantes para 2015. La campaña “Esto es Nueva York” potencia la imagen de la ciudad como un lugar único, cosmopolita y emocionante, en el que el visitante será capaz de vivir experiencias que no logrará encontrar en otros lugares. Este precepto -que entronca con la imagen de Nueva York potenciada a través de las series de televisión- junto a la inclusión de las rutas guiadas comentadas en este trabajo en la campaña de promoción turística de la ciudad, viene a confirmar la idea de que las series de televisión de las últimas dos décadas son un elemento activo y dinámico del desarrollo de la imagen de la ciudad y una de las herramientas de captación de turistas. Según datos recogidos en NYC \& Company -la organización oficial de marketing y turismo de la ciudad de Nueva York-, la afluencia de visitantes extranjeros a la ciudad aumentó de 6.8 millones en 2000 a 8.7 millones en 2009 -de los cuales, 360.000 fueron españoles, cifra mayor que la de años anteriores. Desde 2003, el ascenso del número de visitantes internacionales aumentó progresivamente, alcanzando el máximo de la década en 2008, con 9.5 millones de turistas.

Los actos terroristas del 11 de septiembre supusieron un descenso considerable de las visitas internacionales a Nueva York. La mayoría de series norteamericanas optaron 
por invisibilizar los acontecimientos del 11-S. Sin embargo, algunas incluyeron los actos terroristas en sus tramas -como El ala oeste de la Casa Blanca, que no se podía permitir ignorar el asunto-, mientras otras elaboraron sentidos homenajes a la ciudad de Nueva York sin hacer referencia al 11-S -como Sexo en Nueva York, que inauguraba su quinta temporada con su protagonista abandonando la búsqueda del hombre de su vida para comprometerse románticamente con su ciudad. Es por este hecho que no podemos hablar de la influencia de las series de televisión en el descenso de las visitas internacionales a Nueva York. Sin embargo, es curioso comprobar que precisamente tras el 11-S, las audiencias televisivas de la serie neoyorquina más exitosa, Friends, alcanzaban su máximo histórico. En oposición a la búsqueda de experiencias reales análogas a las que viven los personajes de las series de televisión en la ciudad de Nueva York, el público televisivo se refugió en la ficción escapista de los relatos ficcionales que ofrecía la Nueva York falseada de la popular sitcom.

\section{Conclusión}

Del presente análisis, concluimos que las series de televisión ambientadas en Nueva York que han disfrutado de éxito internacional en las dos últimas décadas se han constituido como elementos comunicativos que han contribuido a la forja de una imagen de marca de la ciudad, que promocionada por los distintos aspectos narrativos e icónicos de las series ha atraído a consumidores-visitantes, y ha sido utilizada de manera activa por las campañas de promoción turística de la ciudad.

La tendencia de las series de televisión ha sido potenciar los actuales aspectos positivos de una ciudad castigada por los estigmas de la droga y la delincuencia en la década de los ochenta. Como hemos visto, series como Friends, Sexo en Nueva York o Cómo conocí a vuestra madre llevan a cabo una campaña -no podemos deducir si consciente o inconsciente- de recuperación de prestigio de la ciudad, que destaca las ideas de vanguardia, prosperidad económica y dinamismo. El alcalde Bloomberg utiliza el reclamo de las series de televisión como un elemento más de su campaña, a través de los tours organizados, para su promoción institucional a nivel internacional de la ciudad, con el propósito global de “maximizar el viaje y las oportunidades turísticas a través de los cinco boroughs, construir una prosperidad económica y 
difundir la imagen dinámica de la ciudad de Nueva York alrededor del mundo” (NYC \& Company).

Ahora más que nunca podemos ampliar la noción de 'turismo inducido por el cine', añadiéndole la cada vez más importante variable de la ficción televisiva. Los imaginarios creados por las series de televisión transportan al espectador a universos ficcionales que evocan escenarios reales y les conducen hacia el deseo de recrear lo visto en la pequeña pantalla. El hecho de que la difusión de las series sea cada vez más amplia y multiplataforma nos lleva a concluir que la continua exposición incita a los espectadores a viajar a los lugares mostrados en los productos televisivos.

\section{Referencias bibliográficas}

BALLÓ, Jordi y PÉREZ, Xavier (2005): Yo ya he estado aquí. Ficciones de la repetición. Barcelona, Anagrama.

BAÑOS, Miguel y RODRÍGUEZ, Teresa (2003): Product Placement. Estrella invitada: la marca. Madrid, Dossat.

BIGNELL, Jonathan (2004): An introduction to Television Studies. Nueva York, Routledge.

CASCAJOSA VIRINO, Concepción (2007): La caja lista: Televisión norteamericana de culto. Barcelona, Laertes.

CASCAJOSA VIRINO, Concepción (2005): Prime Time. Las mejores series de TV americanas. De C.S.I. a Los Soprano. Madrid, Calamar Ediciones.

CHAMBERS, Samuel A. (2009): The Queer Politics of Television. Nueva York, I.B. Taurus.

DAHDÁ, Jorge (2005): Publicidad turística. México, Trillas.

GANNON, Martin J. (2004): Understanding Global Cultures. Metaphorical Journeys Through 28 Nations, Clusters of Nations and Continents. California, Sage Publications.

GARCÍA LÓPEZ, Marcial (2001): Publicidad institucional. El estado anunciante. Universidad de Málaga.

GORDILLO ÁLVAREZ, Inmaculada (2009): La hipertelevisión: géneros y formatos. Quito, Ediciones Ciespal.

HALL, Edward T. (1989): El lenguaje silencioso. Madrid, Alianza Editorial.

IMBERT, Gérard (2008): El transformismo televisivo: postelevisión e imaginarios sociales. Madrid, Cátedra. 
LORENZO GONZÁLEZ, José (1988): Persuasión subliminal y sus técnicas. Madrid, Biblioteca Nueva.

MONTES FERNÁNDEZ, Antonia (2007): "El país como marca - crear imágenes a través de la publicidad” en BORRUECO ROSA, María A., El lenguaje publicitario en el turismo. Ediciones Andalucía S.L., pp. 163-174.

RAMOS, Marina (2006): “Cuando la marca ofrece entretenimiento: aproximación al concepto de advertainment” en Questiones Publicitarias, No11, pp. 33-50.

RILEY, Roger et al (1998): “Movie Induced Tourism” en Annals of Tourism Research, Vol. 25, pp. 919-935.

ROSCADO COBIÁN, Carlos y QUEROL FERNÁNDEZ, Piluca (2006): Cine y turismo. Una nueva estrategia de promoción. Sevilla, Albanta Creativos S.L.

VALLS, Josep-Francesc (1992): La imagen de marca de los países. Madrid, McGraw Hill. 